Grand Valley State University

ScholarWorks@GVSU

Peer Reviewed Articles - Public, Nonprofit, and Health Administration

$10-2001$

\title{
A Community of Voices: Using Allegory as an Interpretive Device in Action Research on Organizational Change
}

Joseph W. Grubbs

Grand Valley State University

Follow this and additional works at: https://scholarworks.gvsu.edu/spnha_articles

\section{ScholarWorks Citation}

Grubbs, Joseph W., "A Community of Voices: Using Allegory as an Interpretive Device in Action Research on Organizational Change" (2001). Peer Reviewed Articles - Public, Nonprofit, and Health Administration. 11.

https://scholarworks.gvsu.edu/spnha_articles/11

This Article is brought to you for free and open access by the School of Community and Leadership Development at ScholarWorks@GVSU. It has been accepted for inclusion in Peer Reviewed Articles - Public, Nonprofit, and Health Administration by an authorized administrator of ScholarWorks@GVSU. For more information, please contact scholarworks@gvsu.edu. 


\title{
A Community of Voices: Using Allegory as an Interpretive Device in Action Research on Organizational Change
}

\author{
JOSEPH W. GRUBBS \\ Grand Valley State University
}

\begin{abstract}
Organizational change involves patterns of engagement across organizational lines and thus carries important cultural implications for participants and groups within communities of organizations. This article proposes using allegory as an interpretive device in the study of organizational change. Allegory allows organizational research to appreciate the way "characters" introduce distinct qualities into the change experience. Based on an action research program with public organizations in the state of Delaware, the article reveals the promise of allegory both for explicating theory and informing reflexive practice.
\end{abstract}

Allegory transforms experience into a concept and a concept into an image, but so that the concept remains always defined and expressible by the image.

-Goethe

Change has become a central theme in the study of organizations. During the past decade, scores of articles have been dedicated to exploring the process and management of change (Kahn, 1993; Kim, 1993; Newman \& Nollen, 1998; Van de Ven \& Poole, 1995), and an entire industry has emerged around the practice of change management (Worren, Ruddle, \& Moore, 1999). Although the interest in change among organizational scholars continues to rise, our understanding of the concept remains limited by several flawed assumptions relating to change and to the nature of organizations.

One of the most concerning assumptions, particularly in today's world, leads us to view change as a process that occurs one organization at a time, with our inquiry dedicated to observing change within individual organizations (for examples, see Kotter, 1996; Nadler, 1998; Newman \& Nollen, 1998). Such an image fails to reflect the increasingly complex nature of organizations in the postindustrial era. As organizations from all sectors continue to forge joint ventures, strategic alliances, and other collaborative relationships, we must think of change as involving and affecting entire organizational communities (Bardach, 1998; Marks \& Mirvis, 1998; O’Toole, 1997; Provan \& Milward, 1995; Spekman \& Isabella, 2000).

Organizational Research Methods, Vol. 4 No. 4, October 2001 376-392

(C) 2001 Sage Publications 
A second flawed assumption constricts our inquiry to the mostly functional, rational aspects of change. Consequently, even when we take into account the dynamic nature of organizational alliances, our focus often remains on issues of organizational design, transaction cost, or the resource dependency underlying the relationships (Alter \& Hage, 1993; Bluedorn, Johnson, Cartwright, \& Barringer, 1994; Elg \& Johansson, 1997; Oliver, 1990; Pfeffer \& Salancik, 1978; Robins, 1987; Thorelli, 1986). We fail to see change as a symbolic process, one that carries important cultural implications for participants and their organizations (Grubbs \& Denhardt, 1999; Lawson \& Ventriss, 1992; Trice \& Beyer, 1984).

In this article, I suggest that organizational scholars should adopt a richer, more meaningful image of change by exploring the symbolic aspects (Alvesson, 1995; Jones, 1996; Smircich, 1983, 1985; Trice \& Beyer, 1984), where participants act according to diverse cultural attributes within their respective organizational communities (Czarniawska, 1997a; Rosaldo, 1989; Wilkof, Brown, \& Selsky, 1995). By understanding change in its symbolic context, it is possible to identify the mostly tacit barriers to change and pattern approaches that reflect culturally influenced interpretations of change processes.

On the other hand, such a goal is limited by similar flawed assumptions as those affecting research into organizational change - namely, that our interpretive inquiry most often is conducted within individual groups. Although we may participate in important research into the symbolic aspects of organizations, we often do so one organization at a time. Our attempt to appreciate cultural influences across multiple groups usually involves piecing together findings from analyses of the respective organizations. The question is, how can we adopt methods of organizational research to take account of the complex nature of change while appreciating the cultural significance of change across organizational communities?

This article discusses my use of the literary form, allegory, as a narrative device to examine the symbolic aspects of change across an alliance of public sector organizations in the state of Delaware. My role was as an action researcher, and not as an ethnographer, and my purpose was to understand the cultural factors affecting the change and then to use this insight to inform my intervention into the change process. At the heart of my action research program was the need to look beyond the more rational, structural issues and to unveil the tacit barriers, which emanated from the belief systems of participating organizations (Argyris, 1993; Argyris \& Schon, 1978, 1985; Grubbs \& Denhardt, 1999). To do this, I used qualitative methods to explore the cultural attributes of participating organizations and the way these attributes influenced the shared-change experience. Allegory, as an interpretive device, provided a lens that allowed me to more effectively view the cultural factors affecting the change process.

From the standpoint of literary theory, allegory is an extended metaphor in which authors employ narrative devices to convey a more symbolic meaning than is otherwise apparent in the text (Madsen, 1996; Ortony, 1993). In the context of my research, allegory was used at various points in the action research program to analyze findings from my qualitative inquiry and to present these findings, along with my interpretations, to the other participants. Allegory first offered a way for me to make sense of the various themes from the change, in particular the images of the change as expressed by participants based on their respective organizational belief systems. For example, the more traditional agencies, whose principal value tended to be efficiency, spoke with a "voice" that characterized the change as a way to increase productivity and cut operat- 
ing cost; agencies that were more concerned with effectiveness expressed themselves in a voice oriented more toward enhancing the quality of service.

As I examined participant narratives during the creation of the research text, I framed my interpretation around these voices to see how they reflected the cultural influences underlying the change experience. Allegory as an interpretive device provided a forum in which the metaphorical characters could interact and through which I could appreciate the symbolic significance of this interaction. During this phase, I was able to place the characters into a fictional plot and to see the way organizational assumptions and value systems came into contact during the story of change.

Allegory also was used during the creation of my public text, the actual narrative I revealed to participants and other readers. I presented the allegory first by itself, allowing the reader to experience the symbolic narrative in an abstracted form, removed from the local context. Next, I provided overlays of my interpretive comments and of actual statements from the participants, thus enabling the reader to see my interpretations of the mostly symbolic aspects of the change and to recognize how these aspects influenced the change process. Through this public text, I was able to stimulate a dialogue relating to the tacit barriers to change and to facilitate consensus building across the organizational community on more meaningful, culturally sensitive patterns of change.

\section{On Allegory}

Goethe's quote in the epigraph reveals the symbolic power of allegory, in particular its capacity to transform human experience first into an abstract notion and then into an enduring image. The etymology of the word stems from the Greek root allos or "other" and agoria or "speaking," with the term other-speaking referring to the presence of a level of meaning below the surface of the text (Leeming \& Drowne, 1996; also Clifford, 1986, p. 99). In its classical form, allegorical literature can be traced to Greco-Roman and Judaic origins, and it features the use of literary devices to communicate moral, philosophical, or other messages beneath a veil of abstraction (see also Whitman, 1987).

Take as an example two allegorical narratives from Western literature: John Bunyan's The Pilgrim's Progress (1678/1987) and Nathaniel Hawthorne's Young Goodman Brown (1835/1967). On the surface, the works share common characteristics. Both depict their protagonists on a journey toward some mystical experience, with symbolic devices used to reveal various religious themes. Yet, the "other meaning" of the allegory tells a different tale. Bunyan's is the story of Christian, a personification of the model Puritan whose path symbolizes the trials of the righteous in the earthly domain. Hawthorne's, on the other hand, offers a critique of Puritan society, a tale of corruption, spiritual guilt, and moral hypocrisy. Although similar in form, the narratives yield very different images of early Anglo-American religious practice (for discussion, see Grubbs \& Denhardt, 1999).

In the study of culture and organizations, several authors have employed allegory as a way of discussing diverse levels of meaning. The literary form, in this regard, most often has been adopted as an interpretive device-a framework to help make sense of the different frames of reference underlying the respective fields. For example, Clifford (1986) suggested that the entire practice of ethnography could be viewed as allegorical in nature. He wrote, 
Ethnographic texts are inescapably allegorical ... [and] the very activity of ethnographic writing - seen as inscription or textualization-enacts a redemptive Western allegory.... Allegory (more strongly than "interpretation") calls to mind the poetic, traditional, cosmological nature of such writing processes. (pp. 99-100)

Citing Shostak's classic study, Clifford traced the diverse allegorical voices in the ethnographic narrative. These voices, Clifford concluded, reflect the different meanings that occur, both for the ethnographer and the reader, and have significant implications for the knowledge that follows from the ethnographic experience.

For Clifford (1986), the principal concern is how the meaning from ethnographic accounts transcends the "simple" incidents in their local context and, with the multiple layers of interaction between author, reader, and text, becomes part of a broader narrative of human experience. The cultural norms and lifeways of the !Kung described by Shostak, in particular those of the woman, Nisa, go beyond their time and space significance-that is, a point in time in the Kalahari Desert. Due to the process of ethnographic research, as it reveals the many voices that appear in the text, these elements of culture become transformed to have what Clifford called "transcendent meaning" (p. 99). He wrote,

[Allegory] draws attention to aspects of cultural description that have until recently been minimized. A recognition of allegory emphasizes the fact that realistic portraits, to the extent that they are "convincing" or "rich," are extended metaphors, patterns of associations that point to coherent (theoretical, esthetic, moral) additional meanings. (p. 100)

In organization theory, Frost, Moore, Louis, Lundberg, and Martin (1985) used allegory to present the findings from their meta-analysis of the study of organizational culture. The public text featured a fictional narrative in which different types of birds served as symbols for the way scholars interpret culture in human organizations. The narrative began,

Several spirit birds were flying together, returning from an extensive trip to investigate the cultures of human organizations. The birds had been flying for a long time and, as they were weary, they stopped to rest on a large rock. In the group were a raven, an owl, a wren, an eagle, a stork, a pelican, and a phoenix. In popular folklore, each of these birds is associated with distinct qualities. . . Each bird was attempting to describe cultural experiences it had had during its travels, for each had found the cultural aspects of human organization particularly fascinating. (pp. 13-14)

The symbolic language of allegory enabled the authors to reveal how different frames of reference may contribute to vastly different understandings of culture, in their case based on an array of papers presented at a conference. They wrote, "Like the individual birds in the [allegorical narrative], each conference participant brought along a different perspective on organizational culture" (p. 24).

As with the allegory of ethnography described by Clifford (1986), the different voices present in Frost et al.'s (1985) symbolic narrative of organizational culture take on meaning at several levels. In one sense, the figures represent the different viewpoints from the particular conference, and as such they reflect the various images of culture in the field of organization theory. This ties the narrative to the local context of the participants. However, the true meaning comes out as these characters, reflections 
of the different viewpoints, interact in a symbolic discourse. This is the other meaning of the allegory, or the "transcendent meaning," to use Clifford's phrase, in which the significance of the engagement extends beyond the local context. The narrative is not a history of the conference, nor is it a rational summary of the conference papers. Rather, it is an extended metaphor that takes on meaning at a variety of levels, and it is this broader meaning that allegory enables the authors to capture and present to the reader.

Weick (1996) also adopted allegory for the purpose of engaging in a meta-analysis of existing scholarship, in this case on the 40th anniversary of the publication of Administrative Science Quarterly. He used the Mann Gulch and South Canyon wildfire tragedies, in which firefighters refused to drop their "heavy tools" and consequently lost their lives, as a reflection of the traditionalism in organization theory. $\mathrm{He}$ wrote,

Dropping one's tools is a proxy for unlearning, for adaptation, for flexibility, in short, for many of the dramas that engage organizational scholars. It is the very unwillingness of people to drop their tools that turns some of these dramas into tragedies. . . . Social scientists refuse to drop their paradigms, parables, and propositions when their own personal survival is threatened. To drop one's tools, then, is an allegory for all seasons that is capable of connecting the past with the present. (pp. 301-302)

For Weick, this symbolizes the tendency of organization theorists to retain their conceptual baggage and, as a result, remain stagnant in their studies of human organization.

My use of allegory differs in scope from the other adaptations in ethnography and organization theory, but the principles remain the same. The purpose of borrowing the literary form is to use it as an interpretive device for exploring processes of change across communities of organizations. As such, allegory can be understood as an extended metaphor in which characters or objects in the narrative represent unique cultural attributes from their respective organizational communities (on the use of complex metaphor, see Czarniawska, 1997b). By cultural attributes. I am speaking of the social influences of human action, what Geertz (1973) referred to as "plans, recipes, rules, instructions" (p. 44). These attributes allow group members to make sense of their surroundings, to adapt, integrate, and respond to various factors in their social settings. Over time, such attributes become shared within the group and manifested in the beliefs and actions of individual members (Ingersoll \& Adams, 1992; Schein, 1997).

Despite the inherent cultural diversity, organizations that have undergone a similar formative process or that share comparable characteristics in their value systems may exhibit some of the same cultural attributes. Human actors from these groups may come together with representatives from other groups, based on the shared assumptions and beliefs underlying their otherwise distinct organizational cultures. The cultural attributes that become shared across organizations in networks and that emerge around issues of organizational change serve as the building blocks of the allegory. The literary form offered a way for me to understand these influences and their implications for organizations engaged in a shared-change experience. Specifically, allegory was used as an interpretive device that enabled me to unravel the oral and textual narratives from the participants and to appreciate the various cultural factors from the community of organizations. 


\section{Case Study: Allegory and Change in the State of Delaware}

To explicate the notion of allegory as an interpretive device, it may be helpful to consider a case study based on my involvement in a change process in the state of Delaware. From 1996 to 1998, I served as a consultant to the state government to facilitate a change initiative involving several of the agencies responsible for human and social service delivery. My role, along with several other colleagues, was to conduct research and analysis on various aspects of the change and to inform the process through research reports, training seminars, and ongoing process and management consultation.

The state of Delaware's change initiative began in 1993, when Governor Tom Carper issued a directive challenging the state government's human and social service agencies to develop an integrated system of service delivery (Carper, 1993; see discussion in Grubbs \& Denhardt, 1999). Carper's executive order brought together cabinet-level secretaries from seven of the state government's lead service organizations, a group that became known as the Family Services Cabinet Council. With backing from executive leadership, most of the functional details of the change process were carried out by executive staff from the Cabinet Council agencies, a group known as the Services Integration Working Group.

My action research consisted of the use of qualitative methods, with a document search, semistructured interviews, and participant observation as my primary strategies for gathering information. First, I conducted a document search to collect historical resources concerning the state of Delaware's service integration agenda. This helped me to appreciate the organizational community in its broader social and political context. Documents reviewed included letters, e-mail messages, formal memoranda, and other textual narratives, which were either associated with the change process or with other activities related to the effort. In addition to their substantive relevance, these documents were examined as cultural artifacts, symbols reflecting the deeper significance of the transformation within the Delaware community.

Second, I conducted semistructured interviews with executive staff from the Services Integration Working Group. I determined that this would be a key level of analysis because the group consisted of the primary architects of the change initiative and represented a microcosm for the formation of culture within an organizational community. Despite ties to their respective organizations, working group members for several years had engaged on this particular change process, as well as other policy and administrative issues. I found that such engagement had enabled them to establish a sense of trust and shared communication, important characteristics for the formation of an organizational community (Adams \& Ingersoll, 1990; Schein, 1997).

Third, a similar group of semistructured interviews was conducted with cabinet secretaries who make up the Family Services Cabinet Council. These individuals served as a source of executive leadership for the network in the overall change experience and therefore offered a unique perspective on leading change and facilitating collaboration within the emerging social service network. In a broader sense, interviews with these individuals provided valuable insight into the nature and role of leadership in the state of Delaware.

My goal during the information collection phase involved identifying the key sources of oral and textual narratives, then gathering from these sources narratives 
relating to the change process. Of interest also were my field notes, which contained important information and reflections from my engagement with the research participants. The narratives, both from the participants and myself, were then catalogued, analyzed, and coded through a process of selection that enabled me to highlight diverse images of the shared change.

During the research process, I faced several important ethical challenges. First, although wanting to maintain the confidentiality of the research participants-for a number of reasons, including protecting them from any negative consequences resulting from their participation - it was my responsibility as an action researcher to ensure accuracy in the research findings. My use of tape recordings and field notes helped in this regard, as I was able to compare my analysis with the interview transcripts and to consider my "readings" in light of the tone and context of information gathering events (Altheide \& Johnson, 1998).

Second, as an action researcher, I was obligated to conduct my inquiry on the basis of informed consent on the part of the participants. This was obtained either using a formal document that explained the confidential and voluntary nature of the research, which the participant was asked to sign, or through a verbal statement at the beginning of the interview, to which the participant would acknowledge in the taped record. (For a discussion of ethical issues, see Christians, 2000.)

The use of allegory as an interpretive device occurred during several phases of my research program: the interpretation phase, the development of the research text, and the final preparation of the public text from my inquiry (Denzin \& Lincoln, 1998; also Van Maanen, 1988). As Czarniawska (1997b) suggested, I employed the literary form as an extended, complex metaphor to understand very complex phenomena surrounding processes of change and to communicate this understanding to the various readers. The purpose of allegory as an interpretive device thus was twofold, first to interpret the themes emanating from the change experience, and second to initiate a dialogue among participants that allowed for a more effective facilitation of the change.

Allegory was first used as a narrative device during the interpretation phase of the research, that is, as a tool to help me make sense of the diverse narratives emerging from the change process. As I reviewed narratives from the participants and from myself as the researcher, I began to notice distinct themes. These themes reflected different images of the change as held by the participants. Moreover, as I delved deeper into the oral and textual narratives, I began to notice that the themes were not random but reflected the belief systems underlying participating organizations.

Central administrative agencies, for example, such as the Budget Office, and the more politically oriented agencies, such as the Governor's Office and the legislative offices, viewed the change as a way of reducing service redundancy and increasing fis$\mathrm{cal}$ and administrative efficiency. On the other hand, service-oriented agencies, such as the Department of Services for Children, Youth and Families, saw the service integration initiative as a way to more effectively provide support for children, families, and communities. Other voices also came forward, such as those focused on the "how" of service integration, with an emphasis on training, technology, and facilitation.

By adopting the narrative device of allegory, I transformed these themes into "characters." The characters were developed according to the values being communicated by the participants. In other words, the characters served as symbols of the cultural attributes of participating organizations and, in turn, reflected the way these attributes became manifested during the change process. However, the characters should not be 
viewed as metaphors of a single organization or participant; rather, they reflected the cultural attributes shared across organizations in the community, personifications of the cultural attributes of organizations with similar value systems. Although beliefs within each respective group varied and each group had its own distinct cultural system, important characteristics from these meaning systems were shared between the groups.

Table 1 provides a list of the characters from my interpretation of the change experience and the cultural attributes they symbolized. For instance, charity personified the more service-oriented agencies within the state of Delaware, agencies whose primary values centered on serving children and families. Members of these organizations interpreted the change experience as a way of enhancing the quality and accessibility of state services for families. Thrift, on the other hand, represented those agencies whose primary values focused on fiscal efficiency. Agencies with cultural attributes portrayed by thrift tended to view the change as a way of "doing more with less."

The allegorical figures became lenses for me during the interpretive phase of my research, devices that enabled me to appreciate the ways in which cultural attributes from diverse organizations affected the change process. When I interviewed participants or combed through documentary texts, I heard the voices of these characters speaking to me (figuratively, of course!), communicating important insights concerning themselves and their organizational value systems. As the interpretive phase of my research unfolded, I was able to engage in a dialogue with these characters, thereby gaining a richer appreciation of the frames of reference underlying the organizational drama.

My use of allegorical characters was not some reductionist attempt to set parameters on, or to generalize, the diverse meaning systems within participating groups. The goal was not to construct organizational or cultural "types." Even if this were possible, which from my standpoint it is not, such an approach would fail to take account of the unique system of beliefs within each group (Alvesson, 1995; Frost et al., 1985; Sackmann, 1992, 1997; Schein, 1983, 1997). Instead, the use of allegory enabled me to interpret the ways in which attributes from these belief systems emerged around, and in many ways influenced, the change experience. The attributes were shared by multiple organizations, due to common traits in the groups' meaning systems, and reflected the way members of these groups made sense of the change.

The second use of allegory occurred during the preparation of the research text, or the interpretative narrative I prepared to make sense of the symbolic meaning underlying the change process (Denzin \& Lincoln, 1998). As I engaged in my interpretation of the qualitative material, I saw the characters begin to form as symbols of the various sets of cultural attributes. Besides being important as symbols, however, the characters took on a deeper significance through their interaction in the shared-change experience. In this regard, the allegorical narrative I created as the researcher, my research text, became the forum in which the characters could interact.

My development of the research text actually became a process of creative writing. In fact, the research text itself was a fictional narrative. Before endeavoring in this process, I read allegories from several authors to see the way they introduced characters, designed plots, presented action, and other literary techniques. Thanks to this review of allegorical literature, I began to see the characters in a new light. They ceased being simply metaphors for the various frames of reference, but in a figurative sense, they became living and breathing creatures. My desire was to get to know these characters, 
Table 1

Characters in the Delaware Allegory

\begin{tabular}{|c|c|}
\hline Charity & $\begin{array}{l}\text { Symbolized the service-oriented organizations in the Delaware network, those } \\
\text { with the well-being of children and families as their primary value. The organiza- } \\
\text { tions represented by this character shared an appreciation of group collabora- } \\
\text { tion, with the main goal of supporting children and families. }\end{array}$ \\
\hline Thrift & $\begin{array}{l}\text { Personified the state of Delaware's most politically oriented groups, those } \\
\text { whose primary value centered on accountability for public resources. Prevailing } \\
\text { attributes of these organizations' cultures centered on efficiency, with human } \\
\text { action dedicated to "doing more with less." }\end{array}$ \\
\hline Knowledge & $\begin{array}{l}\text { Represented groups that shared learning as a common value. On one hand, } \\
\text { they recognized the interorganizational change as an important step for service } \\
\text { delivery, but on the other hand, their primary contribution to the narrative } \\
\text { involved how the change could occur. The organizations symbolized by this } \\
\text { character shared the belief that training would be the most viable course to } \\
\text { integration. }\end{array}$ \\
\hline Technique & $\begin{array}{l}\text { Symbolized organizations that have technique as a core value-that is, the belief } \\
\text { in process efficiency facilitated by technological capacity. The groups viewed } \\
\text { service integration as a technological process, with the only question being } \\
\text { how "it" would happen. Change in the network was less of a service-oriented } \\
\text { phenomenon and constituted more of an integration of existing technological } \\
\text { infrastructures. }\end{array}$ \\
\hline Suspicion & $\begin{array}{l}\text { Reflected those cultural attributes devoted to maintaining their organizations' } \\
\text { respective base of power. These groups believed that the change represented } \\
\text { a direct threat and, consequently, adopted self-preservation as a primary course } \\
\text { of action. The character introduced elements of "turfism" to the dialogue on } \\
\text { integration, which translated into both overt and tacit barriers to change. }\end{array}$ \\
\hline Other & $\begin{array}{l}\text { Personified the ties between individuals working in a network and their original } \\
\text { organizational domains. The character is unique, as he does not serve as a } \\
\text { metaphor of the cultural attributes from a particular group. Instead, he represents } \\
\text { the influence of original organizations generally on collaborative networks. }\end{array}$ \\
\hline Prudence & $\begin{array}{l}\text { Symbolized the cultural attributes in groups that supported Delaware's change } \\
\text { initiative but ones that offered insight into the dialogue. Scholarship and public } \\
\text { service served as the primary values, and these groups engaged with the actors } \\
\text { in a way to facilitate the change experience. }\end{array}$ \\
\hline
\end{tabular}

appreciate them at many levels, and enlist their support in my understanding of the way the different frames of reference in the organizational community affected the change process.

In the research text, I placed the voices into a dialogue-one that, although removed from the local context in the state of Delaware, provided a glimpse into the Delaware change. The allegorical figures were allowed to roam freely in their fictional universe and to engage with each other based on their respective frames of reference. In doing so, they yielded valuable insight into the factors affecting the change process. Allegory, as an interpretive device, provided the narrative stage for me to experience and then to understand the "other meaning" of the engagement between the various systems of belief.

The research text also provided the forum for me to construct a variety of scenes to determine how the service-oriented character, Charity, would interact with the more efficiency-minded Thrift. Would the two characters form a consensus and join together in the journey? Or, would they remain distant from the other, making attempts 
to effect the change based on their own frame of reference? And what of the other characters? What part would they play in the change? The allegorical form enabled me to appreciate the characters as personifications of their respective value systems but also to recognize the way they added to a deeper meaning of the change experience. Through the allegory, I captured the pervasive impact of participants' meaning systems on the change and to understand the implications of this impact for the organizational community. Moreover, I was better able to see my influence as the researcher as I become a character in the allegorical narrative.

The third use of allegory occurred during the creation of the public text, or the narrative that I presented to the other participants and to the scholarly community. My purpose for using allegory in this phase was to highlight for discussion the mostly symbolic aspects of the change but to do so without raising defensive routines among the participants. Of course, this required careful consideration of my relationship with the reader. As Rabinow and Sullivan wrote, texts are "plurivocal, open to several readings and to several constructions" (cited in Riessman, 1993, p. 14), and I wanted to use the forum of the public text to form a bond with those who may come into contact with the public narrative. The readers would serve first as filters, interpreting the story based on their sociocultural context, then as conduits between the text and others around them (Clifford \& Marcus, 1986; Riessman, 1993).

To present the allegory in the public text, I adapted a framework similar to that used in the learning history, a process developed by scholars in the Society for Organizational Learning (Roth, 1996; Roth \& Kleiner, 1995) and similar to Argyris's (1993) approach to providing feedback in an action research program. Specifically, I structured the presentation in three ways: first, the allegory by itself as a prose narrative; second, with an overlay of my interpretive comments; and third, with actual excerpts from the participants in the Delaware change. In this way, the allegory was offered first as an abstraction from the individuals and events surrounding the shared-change process, then along side the overlays, which revealed the story's other meaning.

Tables 2 and 3 show selections from the allegory in the left column, with my commentary and the actual statements from participants on the right. The fictional narrative allowed readers to experience the symbolic aspects of the change, whereas the overlay of my interpretive comments enabled them to appreciate how these symbolic aspects affected the change process. The selections in Table 2 concentrate primarily on contextual issues. My commentary in this regard represented an overall reading of the change experience, with the primary intent of communicating my interpretations of the purpose and scope of the change. In this way, participants were encouraged to engage in reflexive practice- that is, to look at how their own interpretations of actions and events contributed to the way these events were constructed within the organizational community.

The other meaning of the allegory becomes more apparent in Table 3 , as I introduce the allegorical characters. Here, the reader is able to see the characters as symbols, reflections of the various cultural attributes, and the way the characters interact, based on my interpretation of the attributes that they personified. As discussed previously, such elements of the allegorical narrative were derived through analysis of the communication patterns that I experienced during the research process. My approach involved using the overlays of transcripts from the semistructured interviews to further illustrate the connection between what was said and the value system that contributed to the narrative's meaning. The intent, to reveal the deeper significance of language, artifacts 
Table 2

Interpretation of Network Context

Charity awoke from a horrible dream: She had seen a family wandering in the wilderness, weak and without food or shelter. After hours of stumbling across the barren landscape, the family came upon a house.

It was not an assuming house, its sides and roof weathered, but it seemed larger than it actually was because of its imposing front door. Cast iron and a full 2-feet thick, the door was like an entranceway one might have found on a medieval castle, or a walled city, impenetrable. The father of the family reached with his tired hand and knocked as hard as he could. But given the weight and breadth of the door, his knock barely rose above the tempest that scoured the wilderness behind them. Again he knocked, but knew that certainly no one would hear. Finally, when the family had turned to leave, a sound of latches being unfastened came from the other side.

The door cracked open, and a face peered through. It was not an unfriendly face, but it certainly did not show the warmth the family had hoped for; it was not a face that promised comfort from the storm. "May I help you?" asked the face, for the family could see nothing more.

"My family has been ravaged by the storm," the father said, trying to keep his voice from trembling. "We have no food or shelter. Our children are in need. Can you help us?" "We do not offer food or shelter here," said the face. "And there is no doctor to help your children. We have only water. For the other things, you must continue through the wilderness to the other houses. At each, you will find some of what you need."
The current array of services, marked by a fragmented and complex system of delivery, as expressed in Governor Carper's (1993) executive order and the Lochtenberg Commission (1993) report.

The imposing nature of government service agencies, particularly those that remain bureaucratic in form.

The fact that much of the labor required for accessing services falls on families as opposed to agencies offering services where they are needed most.

Service delivery systems are not family friendly, instead retaining an agency-based focus.

The categorical, issue-based form of service delivery, which forces families to search out the support they need by going from agency to agency.

and other organizational symbols, and the way these cultural aspects were reflective of the belief systems within participant groups.

The actual unveiling of the allegory in this particular case was indirect; that is, the public text was simply made available to participants for general review and discussion. We did not hold a separate meeting or work session to share our interpretations. This proved to be a major limitation as it failed to generate the type of dialogue necessary to affect the change. The benefit of the allegory, however, even with this limitation is that it provided me with greater insight into the cultural factors affecting the change. In turn, such insight enhanced my effectiveness as a facilitator of the change process. I was able to identify the tacit barriers to change and to inform the level of action among participants necessary to overcome these barriers. 
Table 3

Interpretation of Participant Narratives

\begin{abstract}
As Charity left her house, she came across Thrift, who had experienced a similar dream. Thrift, too, had seen that problems existed in the way people in the land of well-being supported families and recognized that something had to be done.

Charity: "Thrift, I have had a terrible
\end{abstract} dream. I saw a family struggling in the wilderness, trying to find the help they needed, until one by one they died in misery. Our many houses did nothing to help them."

Thrift: "I had a similar dream. I saw our houses leave food, water, and other things outside for a family to partake on their own. And, some houses even offered some of the same resources. This must be changed."

Charity: "We have to work together, to get our houses to share resources and offer food and shelter in ways that families don't have to wander around through the wilderness. Maybe we can even give them what they need all in one place."

Thrift: "I don't know, Charity. I think we need to be more efficient in the way we offer food, shelter, and those other things. We can't just keep all these houses around, or let families keep taking what they need. It just costs too much and the houses keep giving the same thing."

Charity: "Oh, Thrift. I think we just have to be more supportive. It's not the efficiency we should be concerned about as much as it is how effective we are in supporting families, and how simple we can make it for them."

Thrift: "I still think it's all that duplication, one house doing what some of the others are doing, then the fact that they just leave that precious food and water on the doorstep. I mean, families can just keep taking all they need."
In the state of Delaware initiative, two distinct viewpoints emerged relating to the goal of service integration. These can be seen in the following statements:

Member of the Services Integration Working Group: "We need to do better than we're doing, we need to integrate our services. We need to make it less complex for the client and family to navigate . . . taking the complexity and putting it behind the counter, so that the client can focus on their problems and not focus on mastering the system" (confidential conversation, September 18, 1997).

Participant in the state of Delaware's deliberations: "It seems to me ... you're trying to maximize productive uses of your limited resources. And, to the extent that you engage in the duplication of services . . . you're being wasteful and not providing the quantity of services you could optimally provide. That's what's been the problem" (confidential conversation, October 30, 1997).

Working group member: "Despite the fact that we have this marvelous system of state service centers, which is providing the government's services for the most part . . . [state services] were complex. It was a challenge to manage those . . . it was all out there, but it was very hard for the client to navigate through them" (confidential conversation, September 18, 1997).

\section{Assessing Allegory in Organizational Research}

The principal strength of allegory as an approach to narrative analysis in organizational research is that, first, it enables participants to identify key attributes of the values underlying individual groups and then to understand how these attributes affect organizational members' views on the shared-change process. Through a group's patterns of communication, as well as its rituals and myths, insights can be gained concerning the organization's belief system. Points of interest here include how group members share information about themselves, interpret actions and events, celebrate 
and punish behavior, and the tacit system of values that contribute to these manifest actions (Bell, 1997; Ingersoll \& Adams, 1992; Schein, 1997; Smircich, 1983).

Second, allegory as an extended metaphor unveils the hidden meanings that emerge in the context of organizational alliances. As members of organizational communities, we are influenced in our interaction by factors in our respective meaning systems. Most often, these factors are not discussed openly, nor are they immediately recognized without a high degree of reflective practice. Analysis of these factors through the interpretive device of allegory provides organizational research a more suitable approach to understanding the "webs of significance" (Geertz, 1973, p. 5) we as humans construct to make sense of our social and organizational world (Chapple, 1941; Weick, 1995).

Third, the strength of allegory stems from its capacity to capture the "plurivocal" nature of organizational change, particularly as it occurs within communities of organizations. The multiple voices expressed in the allegory allow for a vast range of interpretations. For some, this may seem like a daunting proposition, as if the allegory was releasing the reader into the world with just enough interpretation to be dangerous. Such concerns, of course, have been expressed for interpretive social and organization theory generally (Burrell \& Morgan, 1979; Geertz, 1973) and will no doubt be voiced toward an allegorical perspective. And yet it is this characteristic of the allegory as narrative analysis that I believe will allow the approach to find its way into future research, particularly action research and other forms of reflective inquiry.

Although allegory has great potential for revealing the attributes of culture within communities of organizations, one of its limitations is the superficial simplicity of the story. On one hand, the surface simplicity, by making the story accessible and clear, is exactly what facilitates the communication of the deeper meaning. On the other hand, the relative level of simplicity means that a limited number of characters and contexts can be included in the narrative. For the qualitative researcher, this means that decision rules must be developed to determine which themes or values will be highlighted in the allegory. In addition, in an attempt to distill the narrative interpretation to fit the requirements of an allegorical presentation, the richness of the narrative on which the allegory is founded may be lost (for a discussion, see Eco, 1990).

Likewise, just as with the first strength, the value of allegory as an extended metaphor has a concomitant requirement; that is, the researcher must be a competent writer of fiction for the allegory to successfully unveil the attributes of organizational symbolism. For those lacking experience in the preparation of fictional narratives, this presents an entirely new set of challenges. And beyond the creative element, researchers also must be able to balance the fictional side of the presentation with the analytical side so that the story is clearly grounded in and warranted by the narrative information. A concern here is that the researcher could become lost in the creative element, neglecting the underlying purpose.

It should be noted also that the concept of allegory proposed here should be distinguished from psychoanalytical approaches to organizational inquiry. For example, some have compared my allegorical characters to Jungian archetypes. Although I would never suggest excluding the cognitive dimension of cultural studies, my primary focus when interpreting the narratives lies less on the individual participant and more on the shared cultural attributes that emerge around the issue of the change. Cer- 
tainly, the psychological type of each actor may be important at another level, but for the purpose of my inquiry, I remain more concerned with the cultural influences stemming from organizational meaning systems that affect the way human actors engage in the shared-change experience.

A distinction also should be made between allegory and previous efforts to employ literary forms in the presentation of organizational research, particularly Czarniawska-Joerges and Jacobsson's (1995) use of the populist dramatic style, commedia dell'arte. In many ways, the work should be celebrated for its approach, which was based on literary interpretation and included an actual play with well-developed characters. My concern, however, is that by retaining a close connection between fiction and reality, the narrative may have threatened its own success. The veil of abstraction offered by allegory, in contrast, could help to reduce individual and group defensive routines and thereby more effectively contribute to organizational learning and change (Argyris, 1993; Argyris \& Schon, 1978, 1985).

In this regard, we have perhaps the most significant role of allegory as a "way of knowing" - that is, as a way of expressing multiple voices and encouraging multiple interpretations of the change experience. By using allegory, researchers may communicate with participants without directly naming individuals involved in the process, thereby diminishing defensive barriers. Likewise, allegory may be employed to elicit participant responses to the research findings, encouraging those involved to write their own allegory. Such a process could result in an identification of obstacles to change in a way that generates more substantive engagement by members of the organizational community.

\section{Conclusions}

Allegory, as an extended metaphor, proved to be an excellent framework to better appreciate the symbolic elements of change within the state of Delaware's organizational community. The interpretive device enabled me to recognize how the diverse meaning systems within the community contributed to human action, and as a result, I became more sensitive to the cultural dimensions in my action research intervention. However, my use of allegory suffered from several key limitations, the most significant of which was in the indirect nature of my presentation of the public text. This yielded inadequate opportunity for the other participants to provide their viewpoints and write their own allegories, and it limited our shared potential to build on the insights as a way of effecting more meaningful, sustainable change.

My limited use of the interpretive device in this particular case should not detract from its potential for future inquiry. Allegory offers participants a way to capture the distinct voices underlying processes of shared change and to recognize the way in which these voices reflect the cultural attributes of their respective organizations. As an approach to action research, allegory also provides a forum to engage participants and to intervene in ways that reduce organizational defensive routines. The literary form may be used as part of a public text in which the participants may be invited to assess themselves and their involvement in the change. In this way, allegory offers promise both as an interpretive device and as a forum for reflexive practice to facilitate the shared-change experience. 


\section{References}

Adams, G. B., \& Ingersoll, V. H. (1990). Culture, technical rationality, and organizational culture. American Review of Public Administration, 20(4), 285-301.

Alter, C., \& Hage, J. (1993). Organizations working together. Newbury Park, CA: Sage.

Altheide, D. L., \& Johnson, J. M. (1998). Criteria for assessing interpretive validity in qualitative research. In N. K. Denzin \& Y. S. Lincoln (Eds.), Collecting and interpreting qualitative materials (pp. 283-312). Thousand Oaks, CA: Sage.

Alvesson, M. (1995). Cultural perspectives on organizations. London: Cambridge University. Argyris, C. (1993). Knowledge for action. San Francisco: Jossey-Bass.

Argyris, C., \& Schon, D. A. (1978). Organizational learning. Reading, MA: Addison-Wesley.

Argyris, C., \& Schon, D. A. (1985). Strategy, change and defensive routines. Cambridge, MA: Ballinger.

Bardach, E. (1998). Getting agencies to work together. Washington, DC: Brookings.

Bell, C. (1997). Ritual. New York: Oxford University Press.

Bluedorn, A. C., Johnson, R. A., Cartwright, D. K., \& Barringer, B. R. (1994). The interface of convergence of the strategic management and organizational environment domains. Journal of Management, 20(2), 201-262.

Bunyan, J. (1987). The pilgrim's progress. London: Penguin. (Original work published 1678)

Burrell, G., \& Morgan, G. (1979). Sociological paradigms and organisational analysis. London: Heinemann.

Carper, T. R. (1993). Executive order number six. Dover: State of Delaware.

Chapple, E. D. (1941). Organization problems in industry. Applied Anthropology, 1, 2-9.

Christians, C. G. (2000). Ethics and politics in qualitative research. In N. K. Denzin \& Y. S. Lincoln (Eds.), Handbook of qualitative research (pp. 133-155). Thousand Oaks, CA: Sage.

Clifford, J. (1986). On ethnographic allegory. In J. Clifford \& G. E. Marcus (Eds.), Writing culture (pp. 98-121). Berkeley: University of California Press.

Clifford, J., \& Marcus, G. E. (Eds.). (1986). Writing culture. Berkeley: University of California Press.

Czarniawska, B. (1997a). A narrative approach to organization studies (Qualitative Methods Series 43). Thousand Oaks, CA: Sage.

Czarniawska, B. (1997b). Narrating the organization. Chicago: University of Chicago Press.

Czarniawska-Joerges, B., \& Jacobsson, B. (1995). Political organizations and commedia dell'arte. Organization Studies, 16(3), 375-394.

Denzin, N. K., \& Lincoln, Y. S. (1998). Introduction: Entering the field of qualitative research. In N. K. Denzin \& Y. S. Lincoln (Eds.), Strategies of qualitative inquiry (pp. 1-34). Thousand Oaks, CA: Sage.

Eco, U. (1990). The limits of interpretation. Bloomington: Indiana University Press.

Elg, U., \& Johansson, U. (1997). Decision making in inter-firm networks as a political process. Organization Studies, 18(3), 361-384.

Frost, P. J., Moore, L. F., Louis, M. R., Lundberg, C. C., \& Martin, J. (1985). An allegorical view of organizational culture. In P. J. Frost, L. F. Moore, M. R. Louis, C. C. Lundberg, \& J. Martin (Eds.), Organizational culture (pp. 13-26). Beverly Hills, CA: Sage.

Geertz, C. (1973). The interpretation of cultures. New York: Basic Books.

Grubbs, J. W., \& Denhardt, R. B. (1999). Collaboration and allegory: Extending the metaphor of organizational culture in the context of interorganizational change. In Research in organizational change and development (Vol. 12, pp. 59-96). Greenwich, CT: JAI.

Hawthorne, N. (1967). Young Goodman Brown. In F. C. Crews (Ed.), Great short works of Hawthorne (pp. 271-284). New York: Harper and Row. (Original work published 1835)

Ingersoll, V. H., \& Adams, G. B. (1992). The tacit organization. Greenwich, CT: JAI. 
Jones, M. O. (1996). Studying organizational symbolism (Qualitative Methods Series 39). Thousand Oaks, CA: Sage.

Kahn, W. A. (1993). Facilitating and undermining organizational change: A case study. Journal of Applied Behavioral Science, 29(1), 32-55.

Kim, D. H. (1993). The link between individual and organizational learning. Sloan Management Review, 35(1), 37-50.

Kotter, J. P. (1996). Leading change. Boston: Harvard Business School Press.

Lawson, R. B., \& Ventriss, C. L. (1992). Organizational change: The role of organizational culture and organizational learning. Psychological Record, 42(2), 205-219.

Leeming, D. A., \& Drowne, K. M. (1996). Encyclopedia of allegorical literature. Santa Barbara, CA: ABC-CLIO.

Madsen, D. L. (1996). Allegory in America: From Puritanism to postmodernism. New York: St. Martin's.

Marks, M. L., \& Mirvis, P. H. (1998). Joining forces. San Francisco: Jossey-Bass.

Nadler, D. A. (1998). Champions of change. San Francisco: Jossey-Bass.

Newman, K. L., \& Nollen, S. D. (1998). Managing radical organizational change. Thousand Oaks, CA: Sage.

Oliver, C. (1990). Determinants of interorganizational relationships: Integration and future directions. Academy of Management Review, 15(2), 241-265.

Ortony, A. (1993). Metaphor and thought (2nd ed.). Cambridge, UK: Cambridge University Press.

O’Toole, L. J., Jr. (1997). Treating networks seriously: Practical and research-based agendas in public administration. Public Administration Review, 57(1), 45-52.

Pfeffer, J., \& Salancik, G. R. (1978). The external control of organizations. New York: Harper and Row.

Provan, K. G., \& Milward, H. B. (1995). A preliminary theory of interorganizational network effectiveness: A comparative study of four community mental health systems. Administrative Science Quarterly, 40(1), 1-32.

Riessman, C. K. (1993). Narrative analysis (Qualitative Methods Series 30). Newbury Park, CA: Sage.

Robins, J. A. (1987). Organizational economics: Notes on the use of transaction cost theory in the study of organizations. Administrative Science Quarterly, 32(1), 68-86.

Rosaldo, R. (1989). Culture and truth. Boston: Beacon.

Roth, G. (1996). Learning histories: Using documentation to assess and facilitate organizational learning. Working paper, Center for Organizational Learning, Massachusetts Institute of Technology, Cambridge, MA.

Roth, G., \& Kleiner, A. (1995). Learning about organizational learning: Creating a learning history. Working paper, Center for Organizational Learning, Massachusetts Institute of Technology, Cambridge, MA.

Sackmann, S. A. (1992). Culture and subcultures: An analysis of organizational knowledge. Administrative Science Quarterly, 37(1), 140-161.

Sackmann, S. A. (Ed.). (1997). Cultural complexity in organizations. Thousand Oaks, CA: Sage.

Schein, E. H. (1983). The role of the founder in creating organizational culture. Organizational Dynamics, 12(1), 13-28.

Schein, E. H. (1997). Organizational culture and leadership (2nd ed.). San Francisco: Jossey-Bass.

Smircich, L. (1983). Concepts of culture and organizational analysis. Administrative Science Quarterly, 28(3), 339-358.

Smircich, L. (1985). Is the concept of culture a paradigm for understanding organizations and ourselves? In P. J. Frost, L. F. Moore, M. R. Louis, C. C. Lundberg, \& J. Martin (Eds.), Organizational culture. Beverly Hills, CA: Sage. 
Spekman, R. E., \& Isabella, L. A. (2000). Alliance competence. New York: John Wiley.

Thorelli, H. B. (1986). Networks: Between markets and hierarchies. Strategic Management Journal, 7(1), 37-51.

Trice, H. M., \& Beyer, J. M. (1984). Studying organizational cultures through rites and ceremonials. Academy of Management Review, 9, 653-669.

Van de Ven, A. H., \& Poole, M. S. (1995). Explaining development and change in organizations. Academy of Management Review, 20(3), 510-540.

Van Maanen, J. (1988). Tales of the field. Chicago: University of Chicago.

Weick, K. E. (1995). Sensemaking in organizations. Thousand Oaks, CA: Sage.

Weick, K. E. (1996). Drop your tools: An allegory for organizational studies. Administrative Science Quarterly, 41(2), 301-313.

Whitman, J. (1987). Allegory. Cambridge, MA: Harvard University Press.

Wilkof, M. V., Brown, D. W., \& Selsky, J. W. (1995). When the stories are different: The influence of corporate culture mismatches on interorganizational relations. Journal of Applied Behavioral Science, 31(3), 373-388.

Worren, N.A.M., Ruddle, K., \& Moore, K. (1999). From organizational development to change management: The emergence of a new profession. Journal of Applied Behavioral Science, 35(3), 273-286.

Joseph W. Grubbs is an assistant professor of public and nonprofit administration at Grand Valley State University in Grand Rapids, Michigan. He completed his Ph.D. in urban affairs and public policy at the University of Delaware. His published work has appeared in the Journal of Organizational Change Management, the JAI Press series, Research in Organizational Change and Development, Public Administration Review, the American Review of Public Administration, the International Journal of Public Administration, the online Journal of Public Administration and Management, and forthcoming in Public Organization Review. He is also a coauthor of the forthcoming book, Public Administration: An Action Orientation, 4th edition (Harcourt Brace). 